\title{
Investigation of mutations in the SRY, SOX9, and DAX1 genes in sex reversal patients from the Sichuan region of China
}

\section{Chen, X.P. Ding, X. Wei and L.X. Li}

Bio-resource Research and Utilization Joint Key Laboratory of Sichuan-Chongqing, Institute of Medical Genetics, College of Life Science, Sichuan University, Chengdu, China

Correspondence author: X. P. Ding

E-mail: Brainding@scu.edu.cn

Genet. Mol. Res. 13 (1): 1518-1526 (2014)

Received December 10, 2012

Accepted June 28, 2013

Published March 12, 2014

DOI http://dx.doi.org/10.4238/2014.March.12.4

\begin{abstract}
We investigated the molecular genetic mechanism of sex reversal by exploring the relationship between mutations in the sex-determining genes $S R Y$, SOX9, and DAX1 with genetic sex reversal disease. Mutations in the three key genes were detected by polymerase chain reaction (PCR) and sequencing after karyotype analysis. The mutations detected were then aligned with a random sample of 100 normal sequences and the NCBI sequence database in order to confirm any new mutations. Furthermore, the copy number of SOX9 was measured by fluorescence quantitative PCR. Seven of the 10 male sex reversal patients $(46, \mathrm{XX})$ contained an excess copy of the $S R Y$ gene, while one of the eight female sex reversal patients (46, $\mathrm{XY}$ ) was lacking the $S R Y$ gene. Additionally, a new mutation (T-A, Asp24Lys) was detected in one female sex reversal patient (46, XY). No other mutation was detected in the analysis of SOX9 and DAX1, with the exception of an insertion mutation (c.35377791insG) found in the testicular-specific enhancer (TESCO) sequences in an $S R Y$-positive
\end{abstract}


female sex reversal patient (46, XY). Eight of the 18 sex reversal cases (44.4\%) showed obvious connections with $S R Y$ gene translocations, mutations, or deletions, which was significantly higher than that reported previously $(33.3 \%)$, indicating a need to further expand the range of sample collection. Overall, these results indicated that the main mechanism of sex reversal are not associated with mutations in the coding regions of $S O X 9$ and $D A X 1$ or copy number variations of SOX9, which is consistent with results of previous studies.

Key words: Sex reversal; SRY; SOX9; DAX1; Gene mutation; Real-time fluorescence quantitative PCR

\section{INTRODUCTION}

Approximately $1.7 \%$ of newborns present varying degrees of disorders of sex development (DSD) on a global scale (Blackless et al., 2000; Hughes et al., 2006). DSDs are most often manifested when an individual's sex chromosomes or gonads do not match their external gender, or when the anatomical gender is blurred to different degrees with respect to reproductive organs, such as two sets of reproductive organs. Complete reversal syndrome (sex reversal syndrome, SRS) can be divided into two categories: 46, XX male sex reversal and 46, XY female sex reversal, with probabilities of 1 in 20,000 to 1 in 25,000 and 1 in 10,000, respectively (Jiang et al., 1993; Rajender et al., 2006). Therefore, it is particularly important to study the potential genetic mechanisms contributing to human sexual development disorders.

Research into the molecular biological mechanism of DSDs can result in more accurate diagnoses of the disease, and help to determine more extensive and specific strategies for psychological, endocrinological, surgical, and other clinical treatments. Previous studies have revealed that mutations, deletions, or ectopic changes in several sex-determining genes, SRY, $S O X 9, D A X 1, S F 1$, and WNT4, can result in sex reversal. Changes in gene copy numbers of SOX,$D A X 1$, and $W N T 4$, followed by changes in the level of gene expression, have also been shown to cause sex reversal (Bardoni et al., 1994; Kwok et al., 1995; Jordan et al., 2001). In the present study, we studied three key sex-determining genes, SRY, SOX9, and DAX1, in 18 patients with sex reversal in Sichuan Province, China.

\section{MATERIAL AND METHODS}

\section{Study subjects}

The study subjects were 18 patients who were being primarily treated for infertility after marriage for several years at the Institute of Genetic Medicine of the College of Life Sciences, Sichuan University from January 2010 to October 2012. This study consisted of 10 cases of 46, XX male sex reversal (group A) and 8 cases of 46, XY female sex reversal (group B). Group A presented with the following characteristics: small testes, azoospermia, small penis, Adam's apple, short stature, thyroid hormone levels of $0.56-0.90 \mathrm{ng} / \mathrm{mL}$ (mean value: $0.76 \mathrm{ng} / \mathrm{mL}$ ), follicle-stimulating hormone (FSH) levels of 
21.16-29.45 $\mathrm{mIU} / \mathrm{mL}$ (mean value: $26.64 \mathrm{mIU} / \mathrm{mL}$ ), and luteinizing hormone (LH) levels of $8.86-112.20 \mathrm{mIU} / \mathrm{mL}$ (mean value: $9.94 \mathrm{mIU} / \mathrm{mL}$ ). Group B presented with the following characteristics: primary amenorrhea, immature vulva, immature ovary, immature uterus, clitoral enlargement, FSH levels of 58.98-117.9 mIU/mL (mean value: $89.23 \mathrm{mIU} /$ $\mathrm{mL}$ ), LH levels of 12.37-40.50 mIU/mL (mean value: $26.32 \mathrm{mIU} / \mathrm{mL}$ ), and estradiol levels of 18.86-106.54 pM (mean: $67.54 \mathrm{pM}$ ). In addition, 100 samples of normal control peripheral blood were obtained from married, childbearing volunteers. All patients received the right to informed consent.

\section{Cytogenetic analysis}

Metaphase chromosome karyotype split phase was prepared after culturing the patients' peripheral blood under sterile conditions, and were analyzed using the conventional Gbanding technique. The karyotype analysis was based on the International System for Human Cytogenetic Nomenclature (ISCN); at least 20 karyotypes were observed in each specimen.

\section{DNA sequence analysis}

Five milliliters blood was extracted from patients and normal controls, placed in a vacuum ACD anticoagulant tube, and stored at $-20^{\circ} \mathrm{C}$. Whole blood genomic DNA was extracted with a DNA extraction kit (Anhui U-gene Biotechnology Co., Ltd), and the genomic DNA concentration was determined by the optical density method. Sequences of the entire coding regions of $S R Y, D A X 1, S O X 9$, and the upstream testis-specific enhancer element sequence of $S O X 9$ (TESCO) were amplified with primers shown in Table 1 (Shanghai Invitrogen Biotechnology Co., Ltd); the housekeeping GAPDH gene was used as the internal reference. The PCR system was $25 \mu \mathrm{L}$ in total, containing $1 \mathrm{U}$ Taq DNA polymerase (Takara), 100 ng template DNA, 0.2 $\mu \mathrm{M}$ each upstream and downstream primer, $0.2 \mathrm{mM}$ dNTPs, and $2.5 \mu \mathrm{L}$ buffer. The PCR product was processed by $30 \mathrm{~min}$ of $2 \%$ agarose gel electrophoresis at a voltage of $100 \mathrm{~V}$, and the amplification product was sent to the Shanghai Invitrogen Biotechnology Co., Ltd. for sequencing.

\begin{tabular}{|c|c|c|c|c|}
\hline gene & Primers & Primers sequences $\left(5^{\prime} \rightarrow 3^{\prime}\right)$ & PCR conditions & Size (bp) \\
\hline \multirow[t]{3}{*}{$S R Y$} & SRYI & $\begin{array}{l}\text { GTTGAGGGCGGAGAAATG } \\
\text { TTCTTCGGCAGCATCTTC }\end{array}$ & \multirow[t]{3}{*}{$\begin{array}{l}95^{\circ} \mathrm{C}-4 \min \left(95^{\circ} \mathrm{C}-30 \mathrm{~s}, 51^{\circ} \mathrm{C}-30 \mathrm{~s}, 72^{\circ} \mathrm{C}-30 \mathrm{~s}\right) \\
\times 35 \text { cycles, } 72^{\circ} \mathrm{C}-10 \mathrm{~min}\end{array}$} & 559 \\
\hline & \multirow[t]{2}{*}{$S R Y 2$} & CGTCCAGGATAGAGTGAAG & & 497 \\
\hline & & AAGGAGCATCTAGGTAGGT & & \\
\hline \multirow[t]{5}{*}{$\operatorname{SOX} 9$} & SOX9A & $\begin{array}{l}\text { CGGGTGGCTCTAAGGTG } \\
\text { TTGTGCAAGTGCGGGTA }\end{array}$ & \multirow{3}{*}{$\begin{array}{l}95^{\circ} \mathrm{C}-4 \min \left(95^{\circ} \mathrm{C}-30 \mathrm{~s}, 57^{\circ} \mathrm{C}-30 \mathrm{~s}, 72^{\circ} \mathrm{C}-30 \mathrm{~s}\right) \\
\mathrm{x} 35 \text { cycles, } 72^{\circ} \mathrm{C}-10 \mathrm{~min}\end{array}$} & 823 \\
\hline & \multirow[t]{2}{*}{$\operatorname{SOX} 9 B$} & AGAGGAAGCCGAGTGGT & & 416 \\
\hline & & AGGCGGGACGGAGATAG & & \\
\hline & \multirow[t]{2}{*}{ SOX9C } & ACCGACCACCAGAACTCC & \multirow{6}{*}{$\begin{array}{l}95^{\circ} \mathrm{C}-4 \min \left(95^{\circ} \mathrm{C}-30 \mathrm{~s}, 52^{\circ} \mathrm{C}-30 \mathrm{~s}, 72^{\circ} \mathrm{C}-30 \mathrm{~s}\right) \\
\mathrm{x} 35 \mathrm{cycles}, 72^{\circ} \mathrm{C}-10 \mathrm{~min} \\
95^{\circ} \mathrm{C}-4 \min \left(95^{\circ} \mathrm{C}-30 \mathrm{~s}, 60^{\circ} \mathrm{C}-30 \mathrm{~s}, 72^{\circ} \mathrm{C}-30 \mathrm{~s}\right) \\
\times 35 \text { cycles, } 72^{\circ} \mathrm{C}-10 \mathrm{~min}\end{array}$} & 698 \\
\hline & & TGTATAAATCCCCTCAAAATG & & \multirow{4}{*}{967} \\
\hline \multirow{4}{*}{ TESCO } & \multirow{2}{*}{ TESCOI } & CCGTCTCATACTCTTCATAGACACG & & \\
\hline & & CTGACACTTGGTCATAGCTGTGTTC & & \\
\hline & \multirow[t]{2}{*}{ TESCO2 } & GCAGCTGATTCTTTCCAAGAGTCTG & & \\
\hline & & GCATTGCTAAGTATTGACTCCAGTG & & 675 \\
\hline \multirow[t]{3}{*}{$D A X 1$} & $D A X 1 A$ & CATGGGCGAACACACCGGAGCGCAGCAC & \multirow{3}{*}{$\begin{array}{l}95^{\circ} \mathrm{C}-4 \min \left(95^{\circ} \mathrm{C}-30 \mathrm{~s}, 54^{\circ} \mathrm{C}-30 \mathrm{~s}, 72^{\circ} \mathrm{C}-30 \mathrm{~s}\right) \\
\mathrm{x} 35 \text { cycles, } 72^{\circ} \mathrm{C}-10 \mathrm{~min}\end{array}$} & 715 \\
\hline & \multirow[t]{2}{*}{$D A X 1 B$} & $\begin{array}{l}\text { ACCCCCTGGCCTCTGCGCGAAGTAGGAG } \\
\text { AGCAAAGGACTCTGTGGT }\end{array}$ & & \multirow[t]{2}{*}{520} \\
\hline & & GAGCTATGCTACCTGTTG & & \\
\hline
\end{tabular}




\section{Fluorescence quantitative PCR analysis}

SOX9 copy number changes were detected with quantitative PCR on a SYBR Green dye I SLAN ${ }^{\circledR}$-96P Automatic Medical PCR analysis platform. The third exon of the SOX9 sequence was selected for amplification, the primer sequences were: $\mathrm{F}$ 5'-TGGTCTTTAACTCTGACCGTTACCT-3' and R 5'-TATTCCGGATCTTAATCAGAGAA AGTG-3' (Bardoni et al., 1994), with a product length of $102 \mathrm{bp}$. The housekeeping GAPDH gene was selected as the internal reference; primer sequences: $\mathrm{F}$ 5'-ACGGATTTGGTCGTAT TGGGC-3' and R 5'-CTCGCTCCTGGAAGATGGTGAT-3', with a product length of 216 bp. Samples obtained from married, childbearing, normal men and women were used as the positive control. The PCR system was $20 \mu \mathrm{L}$, containing $10 \mu \mathrm{L} 2 \mathrm{X}$ All-in-One qPCR Mix (Guangzhou Fulengen Co., Ltd), 100 ng DNA template, and $0.1 \mu \mathrm{M}$ primers. The reaction conditions were as follows: $95^{\circ} \mathrm{C}$ denaturation for $10 \mathrm{~min}, 95^{\circ} \mathrm{C}$ denaturation for $20 \mathrm{~s}$, annealing at $61^{\circ} \mathrm{C}$ for $20 \mathrm{~s}, 72^{\circ} \mathrm{C}$ extension for $20 \mathrm{~s}, 40$ cycles, with a final extension at $72^{\circ} \mathrm{C}$ for $10 \mathrm{~min}$. The optimum concentration of the primer was determined by the concentration gradient curve and the melting curve of the PCR in order to avoid experimental error due to primer dimerization and non-specific amplification. Each reaction was repeated three times to obtain average values.

\section{RESULTS}

\section{SRY}

Seven of the 10 male sex reversal patients (46, XX) carried an excess of $S R Y$; only one of the eight female sex reversal patients (46, XY) was lacking $S R Y$, while the rest were positive for this gene (Figure 1). Results of bidirectional sequencing and NCBI sequence alignment of $S R Y$ showed that T was replaced with an A at nucleotide 149 of the SRY gene [upstream of the high mobility group (HMG) box] in one female sex reversal patient (46, XY), as shown in Figure 2. This resulted in a mutation of aspartic acid 24 of the coding region to lysine (Asp24Lys), and clinical data are shown in Table 2. This mutation was not found in any of the 100 normal control samples, and has not been reported to date. Therefore, this result likely reflects a novel mutation.

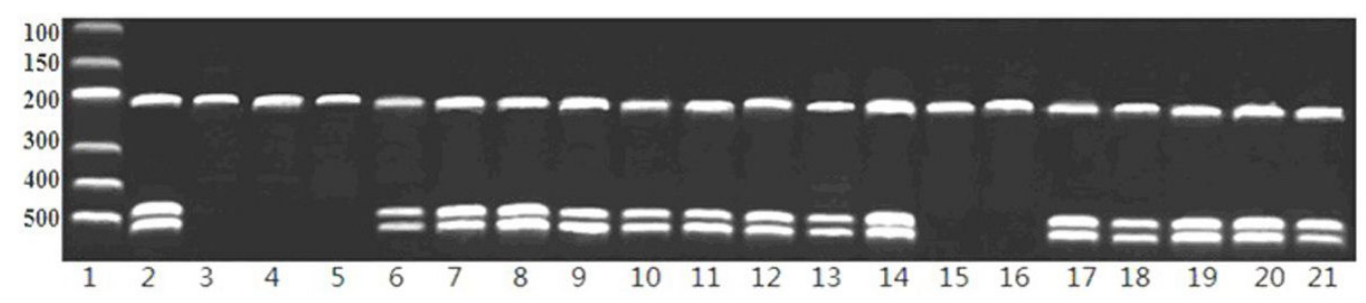

Figure 1. Gel electrophoresis of $S R Y$ gene in 18 case sex reversal patients. Band 216bp is inner reference gene (housing-keeping gene, GAPDH), band 559 and 497bp are $S R Y$ gene. Lane $1=$ marker; lane 2, 3 = control, normal male, female; lane 4, 6, 8-10, 18-20=46, XY female sex reversal patients; lane 5, 7, 11-17, $21=46 \mathrm{XX}$ male sex reversal patients. 


\section{SOX9 and $D A X 1$}

No mutations were found in the coding regions of SOX9 or DAX1 among the 18 sex reversal patients. The upstream TESCO sequence of SOX9 was amplified by PCR and the product was directly sequenced. One insertion mutation (C. 35377791insG) was found in one $S R Y$-positive sex reversal patient (46, XY), as shown in Figure 2; clinical data is shown in Table 2. This mutation was not found in any of the 100 normal control samples and has not been previously reported. Therefore, this mutation is also likely to be novel.

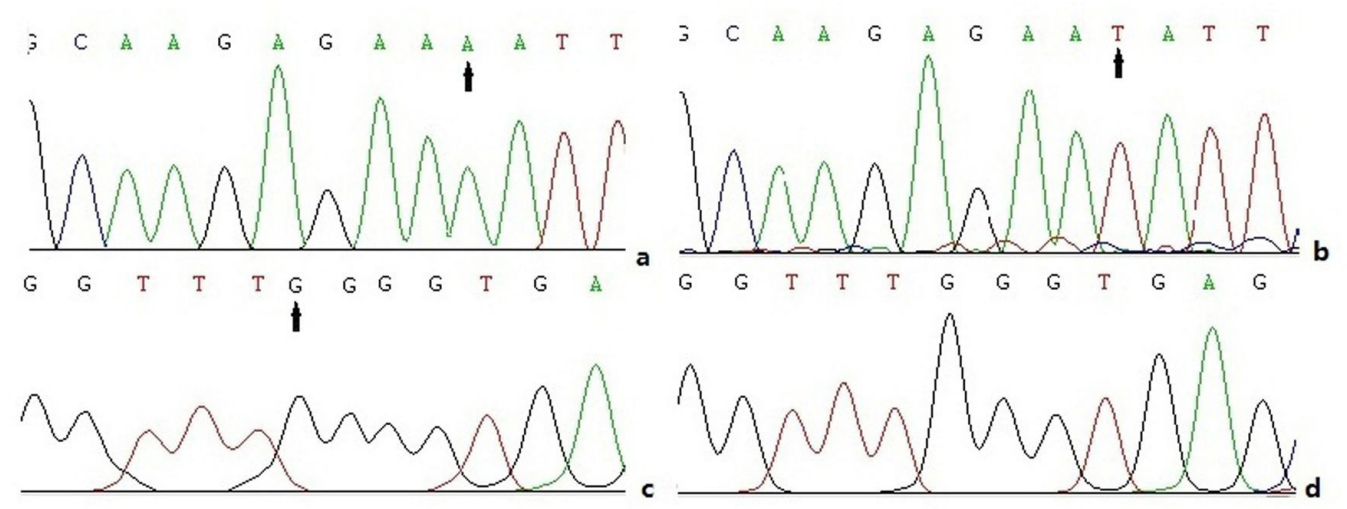

Figure 2. Sequence result of $S R Y, T E S C O$ gene. a. Mutation in 46, XY female sex reversal patients $(\mathrm{T} \rightarrow \mathrm{A}$, Asp24Lys); b. SRY gene sequence of normal control; c. mutation in TESCO region (35377791insG) in 46, XY female sex reversal patients with SRY gene positive; d. TESCO region sequence of normal control.

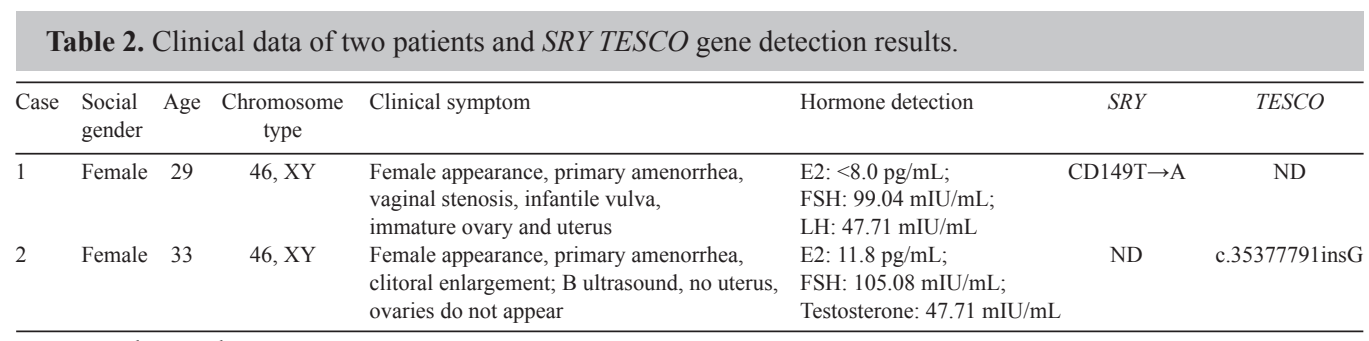

$\mathrm{ND}=$ no detected.

The sequencing detection results described above cannot clearly explain the cause of the 18 cases of sex reversal, as we speculate that the occurrence of sex reversal is instead determined by the expression level of the SOX9 protein, which likely changes depending on the change in the SOX9 copy number. We used the quantitative PCR technique to verify this hypothesis and detected $S O X 9$ copy number changes in three $S R Y$-negative $46, \mathrm{XX}$ male sex reversal patients, and in seven $S R Y$-positive 46, XY female sex reversal patients. No significant differences with the normal control group were found based on calculations using the $2^{-\Delta \Delta C \mathrm{CT}}$ method. The PCR results are shown in Figure 3. 

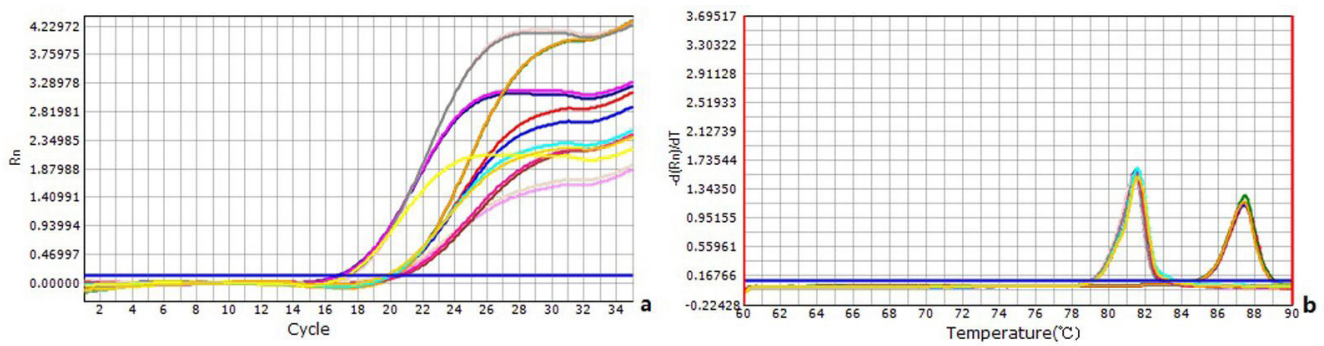

Figure 3. Concentration gradient curve and melting curve of the Fluorescence quantitative PCR. a. PCR amplify curve, the left curve represents $S O X 9$ gene, while the right one represents internal reference GAPDH gene. b. Melting curve of the Fluorescence quantitative PCR, the left curve represents SOX9 gene, while the right one represents internal reference GAPDH gene.

\section{DISCUSSION}

Several 46, XX individuals were found to carry an extra SRY gene, whereas 46, XY individuals were found to have mutations or deletions of this gene. These results confirmed that $S R Y$ is the best candidate sex determination gene (Berta et al., 1990; Abusheikha et al., 2001; Hersmus et al., 2009). However, results of previous studies have shown that mutations or deletions of the SRY gene accounts for only $1 / 3$ of sex reversal cases, implying that $2 / 3$ of the cause of sex reversal remains unclear (Singh and Vutukuri, 2006). Subsequently, genomics, gene structure, and functional analyses revealed that sex reversal was associated with mutations in some other key genes, such as SOX9,DAX1, SF1, and WNT4 (Kwok et al., 1995; Achermann et al., 1999; Hanley et al., 2000). Increases in the copy numbers of $S O X 9$ and DAX1 result in high expression of their corresponding proteins, which in turn leads to sex reversal (Bardoni et al., 1994; Kwok et al., 1995; Jordan et al., 2001). Although the precise mechanism of the expression of these genes is currently unknown, one hypothesis states that in the XY embryo, SRY acts as the testicular differentiation switch, which drives the genital ridge to develop directly into the testis (Sekido and Lovell-Badge, 2008; Rey and Grinspon, 2011).

SRY and SF1 protein complexes bind to a $3.2 \mathrm{~kb}$ testis-specific enhancer upstream of SOX9 (TESCO), causing high expression of the SOX9 protein, which in turn stimulus antiMüllerian hormone expression, and therefore inhibition of the development of the Müllerian ducts. Under the influence of high concentrations of SRY and SOX9 proteins, the genital ridge supporting cells differentiate into Sertoli cells by a self-regulating mechanism. Compared with knowledge of the genes involved in testicular development, ovarian developmental genes remain poorly understood. Regulatory roles in ovarian development have been demonstrated in only three candidate genes (WNT4, DAX1, and FOXL2). Of these genes, only DAX1 was found to be located on the $\mathrm{X}$ chromosome, and was once considered as an ovarian determining gene. However, although genetically modified (Dax1) male mice showed a reversal of gender when $D A X 1$ expression was elevated, Dax 1 mutant females $\left(\right.$ Dax $\left.1^{--}\right)$with reduced DAX1 expression levels showed normal sexual maturation, fertility, and ovulation (Swain et al., 1998). These results indicated that $D A X 1$ is not an ovarian determining gene after all, and it is now generally considered to be an "anti-testis" gene.

The human SRY gene, which is located on the Y chromosome with a full-length of $897 \mathrm{bp}$, was the first gene to be recognized as a testis-determining factor gene. It contains only 
a single exon encoding 204 amino acids, which is a highly conserved sequence belonging to the HMG box motif group of the high-speed mobility class of proteins. Numerous studies have shown that translocations, deletions, and mutations of the SRY gene can cause sex reversal. In the present study, eight of the 18 (44.4\%) cases of sex reversal were found to be associated with the SRY gene, which represents a slightly higher proportion than the $1 / 3$ that has previously been reported (Singh and Vutukuri, 2006). This result may be related to the following facts. First, differences between study subjects; subjects in the present study were all adults as they were seeking treatment for infertility, therefore pediatric data is lacking. Second, results might be biased due to the limited number of specimens. Third, an increased amount of environmental radiation materials may be affecting the human genome. Mutations in $S R Y$ were previously detected in $10-15 \%$ of female sex reversal patients $(46, \mathrm{XY})$, including point mutations and deletions, which were found mostly in the HMG sequence of the SRY gene (Salehi et al., 2006).

A new mutation was discovered in the present study in one female sex reversal patient $(46, \mathrm{XY})$. The site of the mutation lies in the HMG box upstream of the SRY gene, in which T was converted to an A at nucleotide 149, causing mutations in the coding region so that aspartic acid 24 was changed to lysine (Asp24Lys). In this patient, no testes or other male genital organs were found, female genitalia showed significant dysplasia, primary amenorrhea and vaginal stenosis were observed, and the ovary and uterus were immature. Since there was no evidence of abnormalities in $S O X 9$ and $D A X 1$, it was suspected that the occurrence of these symptoms was related to the mutation, pending further experimental verification of functional analysis of the mutant.

The SOX9 gene, which maps to chromosome 17 (17q24.3-25.1), is an important member of the SOX protein family. Because the SOX9 gene is expressed in multiple tissues and since it determines differentiation of the reproductive organs, along with a series of other genes in the genital ridge, it is considered to be an autosomal sex-determining gene. Previous studies have revealed that $2 / 3$ of patients with varying degrees of female sex reversal $(46, \mathrm{XY})$ were associated with cases of short limb dysplasia, and increases in the SOX9 gene copy number can also lead to male sex reversal (46, XX) (Huang et al., 1999; Georg et al., 2010). In transgenic mice with three SRY and SF1 binding sites containing sub TESCO testis-specific enhancements, only full locus mutations resulted in the loss of enhancer activity (Sekido and Lovell-Badge, 2008).

In the present study, no mutation was found in the coding regions of the 18 sex reversal patients and no differences in SOX9 gene copy number were found between the patient group and the normal control group, based on quantitative PCR data, which is in accordance with results of some previous work (Georg et al., 2010). TESCO sequencing results showed one insert mutation (c.35377791insG) in one $S R Y$-positive female sex reversal patient (46, XY). Clinical data showed that this patient had a significant female appearance, no male reproductive organs or glands, primary amenorrhea, and ovary and uterus disease. The occurrence of these traits may be related to the insertion mutation affecting the TESCO enhancer, leading to sex reversal. The functional effects of the mutations will be tested by further experimental validation.

The human DAX1 gene, which is located on the X chromosome (Xp21.1-21.2) with a total length of $4908 \mathrm{bp}$, contains two exons and one intron. It is widely expressed in the adrenal gland and in the hypothalamus-pituitary-gonadal axis, and it plays an important role in the regulation of the adrenal and gonadal systems. Because highly expressed DAX1 in mice has been shown to result in the generation of female sex reversal as a result of gonadal development regulation, it is considered to be an anti-testis gene. DAX1 mutations or deletions cause human adrenal hypoplasia (AHC). Testicles can develop in patients with AHC, which is gen- 
erally accompanied by confusion of testis cords, which promote low attenuation of gonadal sexual function disorders. No mutations were detected in the $D A X 1$ coding region in the 18 patients with sex reversal analyzed in the present study, which confirmed results of a previous study (Hanley et al., 2000).

In summary, we found that complete sex reversal occurred mainly due to mutations of the SRY gene, which accounted for $44.4 \%$ of the 18 cases of sex reversal in patients from Sichuan province. Therefore, although mutations in $S O X 9$ and $D A X 1$ have previously been reported to be associated with sex reversal, these mutations do not appear to be the main cause, which is in accordance with previous work. In addition, two novel mutations were found in $S R Y$ and in the TESCO region.

\section{ACKNOWLEDGMENTS}

Research supported by the Bio-resource Research and Utilization Joint Key Laboratory of Sichuan-Chongqing, Institute of Medical Genetics, College of Life Science, Sichuan University. We are grateful to the patients and volunteers who participated in this study.

\section{REFERENCES}

Abusheikha N, Lass A and Brinsden P (2001). XX males without SRY gene and with infertility. Hum. Reprod. 16: 717718.

Achermann JC, Ito M, Ito M, Hindmarsh PC, et al. (1999). A mutation in the gene encoding steroidogenic factor-1 causes $\mathrm{XY}$ sex reversal and adrenal failure in humans. Nat. Genet. 22: 125-126.

Bardoni B, Zanaria E, Guioli S, Floridia G, et al. (1994). A dosage sensitive locus at chromosome Xp21 is involved in male to female sex reversal. Nat. Genet. 7: 497-501.

Berta P, Hawkins JR, Sinclair AH, Taylor A, et al. (1990). Genetic evidence equating SRY and the testis-determining factor. Nature 348: 448-450.

Blackless M, Charuvastra A, Derryck A, Fausto-Sterling A, et al. (2000). How sexually dimorphic are we? Review and synthesis. Am. J. Hum. Biol. 12: 151-166.

Georg I, Bagheri-Fam S, Knower KC, Wieacker P, et al. (2010). Mutations of the SRY-responsive enhancer of SOX9 are uncommon in XY gonadal dysgenesis. Sex. Dev. 4: 321-325.

Hanley NA, Hagan DM, Clement-Jones M, Ball SG, et al. (2000). SRY, SOX9, and DAX1 expression patterns during human sex determination and gonadal development. Mech. Dev. 91: 403-407.

Hersmus R, de Leeuw BH, Stoop H, Bernard P, et al. (2009). A novel SRY missense mutation affecting nuclear import in a 46, XY female patient with bilateral gonadoblastoma. Eur. J. Hum. Genet. 17: 1642-1649.

Huang B, Wang S, Ning Y, Lamb AN, et al. (1999). Autosomal XX sex reversal caused by duplication of SOX9. Am. J. Med. Genet. 87: 349-353.

Hughes IA, Houk C, Ahmed SF and Lee PA (2006). Consensus statement on management of intersex disorders. Arch. Dis. Child. 91: 554-563.

Jiang SL, Zhang SZ and Yang J (1993). The molecular etiology research of sex reversal syndrome patients. Chin. J. Med. Genet. 10: 18-20.

Jordan BK, Mohammed M, Ching ST, Delot E, et al. (2001). Up-regulation of WNT-4 signaling and dosage-sensitive sex reversal in humans. Am. J. Hum. Genet. 68: 1102-1109.

Kwok C, Weller PA, Guioli S, Foster JW, et al. (1995). Mutations in SOX9, the gene responsible for Campomelic dysplasia and autosomal sex reversal. Am. J. Hum. Genet. 57: 1028-1036.

Rajender S, Rajani V, Gupta NJ, Chakravarty B, et al. (2006). SRY-negative 46, XX male with normal genitals, complete masculinization and infertility. Mol. Hum. Reprod. 12: 341-346.

Rey RA and Grinspon RP (2011). Normal male sexual differentiation and aetiology of disorders of sex development. Best. Pract. Res. Clin. Endocrinol. Metab. 25: 221-238.

Salehi LB, Scarciolla O, Vanni GF, Nardone AM, et al. (2006). Identification of a novel mutation in the SRY gene in a 46, XY female patient. Eur. J. Med. Genet. 49: 494-498. 
Sekido R and Lovell-Badge R (2008). Sex determination involves synergistic action of SRY and SF1 on a specific Sox9 enhancer. Nature 453: 930-934.

Singh R and Vutukuri R (2006). SRY-negative 46, XX male with normal genitals, complete masculinization and infertility. Mol Hum Reprod. 12:341-346.

Swain A, Narvaez V, Burgoyne P, Camerino G, et al. (1998). Dax 1 antagonizes Sry action in mammalian sex determination. Nature 391: 761-767. 